\title{
HACERSE PASAR POR LA QUE UNA NO ES. MODERNIZACIÓN, CRIMINALIDAD Y NO MUJERES EN LA BOGOTÁ DE 1929: UN EJERCICIO DE DECONSTRUCCIÓN Y CONSTRUCCIÓN DE REPRESENTACIONES FEMENINAS
}

\section{HACERSE PASAR POR LA QUE UNA NO ES. MODERNIZACIÓN, CRIMINALIDAD Y NO MUJERES EN la Bogotá de 1929: An Exercise of DeCONSTRUCtion ANd Construction of FEMALE REPRESENTATIONS}

\author{
Ana Alejandra Robles Ruiz* \\ DOI: http://dx.doi.org/10.29043/liminar.v19i2.854
}

Resumen: Reseña de Hacerse pasar por la que una no es. Modernización, criminalidad y no mujeres en la Bogotá de 1929, de María Teresa Garzón Martínez. Tuxtla Gutiérrez, Chiapas: Universidad de Ciencias y Artes de Chiapas, 2018.

Abstract: Review of Hacerse pasar por la que una no es. Modernización, criminalidad y no mujeres en la Bogotá de 1929, de María Teresa Garzón Martínez. Tuxtla Gutiérrez, Chiapas: Universidad de Ciencias y Artes de Chiapas, 2018.

$\square$ 1 libro Hacerse pasar por la que una no es. Modernización, criminalidad y no mujeres en la Bogotá de 1920 (2018), escrito por María Teresa Garzón Martínez, es una propuesta de lectura, desde el giro cultural de los estudios feministas — con base, sobre todo, en la teoría lesbofeminista de Monique Wittig-, del famoso crimen que aconteció en la capital de Colombia en el año de 1922, en el que estuvieron implicadas Eva Pinzón y Raquel Sarmiento. En él la autora hace un ejercicio de deconstrucción de las representaciones —en su mayoría negativas - de las mujeres, visibilizadas en los medios de comunicación a través de la crónica roja de principios del siglo XX y diseñadas por el proyecto de la élite colonial. La autora centra su atención en las representaciones de las mujeres más vulnerables, las de clase baja, las de raza no blanca, las que muestran autonomía sobre sus cuerpos y prácticas sexuales, las que tienen participación por gusto o

* Ana Alejandra Robles Ruiz. Doctora en Humanidades con Énfasis en Literatura por la Universidad de Sonora, México. Docente-investigadora en el Centro de Estudios Superiores de México y Centroamérica de la Universidad de Ciencias y Artes de Chiapas (CESMECA-UNICACH), necesidad en la vida pública de Bogotá —entre estas se encuentran Pinzón y Sarmiento-. A la vez, Garzón imagina y sugiere nuevas representaciones para estas y otras mujeres, partiendo de sustentos teóricos firmes, que nos permiten leer el suceso de 1922, mencionado con anterioridad, como consecuencia del dominio en esa época en el país de la perspectiva blanca, de élite colonial, heterosexual y patriarcal; pero también como la evidencia de la lucha y la resistencia de mujeres que como Eva Pinzón y Raquel Sarmiento se valen de los medios, métodos y prácticas que les son posibles y tienen a su alcance para dejar de ser "no mujeres" — como propone Teresa Garzón- y afirmarse públicamente como mujeres, que se salen del modelo arquetípico de una "buena y verdadera mujer", subalternas, sí, pero finalmente mujeres. Tiene un número total de 173 páginas y se estructura de la siguiente forma: prefacio, introducción, cuatro capítulos, epílogo y bibliografía.

México. Correo electrónico: ale_robbles@hotmail.com. ORCID: https://
orcid.org/0000-0002-6040-5806

Recibida: 23 de septiembre de 2019

Aprobada: 1 de abril de 2020 
Dieciocho años después de haber pasado un periodo en la Biblioteca Nacional de Colombia leyendo crónica roja, como parte de sus labores de asistente de investigación, e inspirada por una crónica que en particular suscitó su interés, la de Eva Pinzón y Raquel Sarmiento, la Dra. María Teresa Garzón Martínez publica el libro que aquí se reseña. Grosso modo en 1922 en Bogotá, que se encontraba en un periodo de transición para pasar de ser una ciudad colonial a ser una urbe moderna a imagen y semejanza de las europeas y estadounidenses, dos jóvenes encuentran en el río San Francisco, cerca del centro histórico -zona en ese entonces habitada por el proletariado urbano, el campesinado inmigrante, vagos y la "plebe" en general一, el cadáver desnudo, desmembrado y con marcas de violencia atroz de una mujer: Eva Pinzón. Según la autora, Pinzón es, desde la representación de la élite colonial, una "no mujer". Esto porque es de clase baja, de raza "inferior", porque se dedica a la prostitución. Es una especie de mujer terrible que, según el discurso de los medios de comunicación impresos de ese entonces - en apoyo a la edificación del mito de la élite-, merece ser desaprobada y despreciada por todos, y además servir de ejemplo para que las mujeres de élite que recién comenzaban a involucrarse con las ideologías feministas y a cuestionar su rol dentro de la sociedad, vieran cuán trágico podía llegar a ser su destino si continuaban queriendo cambiar el estado de las cosas.

Asimismo, Raquel Sarmiento es también una "no mujer" por razones similares a las de Pinzón: es de clase baja, de raza "inferior", se dedica también a la prostitución, pero además después adquirió las etiquetas de asesina, loca y lesbiana. La participación de Raquel Sarmiento en el asesinato de Eva Pinzón es compleja, pero a la vez es clave para entender cuándo y cuáles son las razones que en algún punto puede llegar a tener una mujer para precisamente, como dice el título del libro de Garzón, hacerse pasar por la que una no es. Sarmiento confiesa ser la autora intelectual y material del crimen de Pinzón. Después de caer en contradicciones y de las confesiones posteriores de otras personas, la dejan libre, pues no hay pruebas contundentes que la incriminen. Pero lo importante aquí no es si Raquel es o no culpable, como lo advierte Garzón Martínez, o si en algún momento deseó arremeter contra la vida de Eva Pinzón, sino cuestionarnos iqué la motivó a confesarse como autora del asesinato entregándose a las autoridades, aun siendo inocente? ¿Por qué una mujer querría pagar una condena por algo que no hizo?

Desde luego no hay respuestas definitivas ni unívocas, eso es lo rico del caso que analiza María Teresa Garzón, sin embargo, esta nos lleva a reflexionar profunda y detenidamente sobre las implicaciones de ser una "no mujer" como Eva y Raquel. Y ahí se encuentra el mérito de su trabajo. Desde su perspectiva y desde el resultado de su investigación y análisis, una posibilidad es que Raquel se ve en la necesidad de hacerse pasar por la que no es para tener ante los ojos de los demás, cuando menos, un poco de valor; negativo, sí, pero valor a fin de cuentas. De esta forma no es solo una "no mujer", sino que es también una asesina, una loca y una lesbiana. Su confesión termina siendo una especie de alternativa, una especie de resistencia. Raquel prefiere ser una mujer abyecta, una subalterna, que una "no mujer" que ha permanecido y va a permanecer por el resto de su vida invisibilizada.

Lo que Teresa Garzón logra con Hacerse pasar por la que una no es, es producir conocimiento valioso y de gran trascendencia para entender las problemáticas de las mujeres y las relaciones de poder que cruzan esas problemáticas, pero sobre todo, como dice ella, realiza acción política feminista que da cuenta de la existencia de las mujeres y sus historias desde una perspectiva cultural, con aspiración decolonial. Teresa Garzón, consciente de sus privilegios como mujer blanca, letrada y urbanita, con dolor y con mucha valentía, asume una responsabilidad con las mujeres en plural, al develar en 173 páginas los mecanismos del heteropatriarcado de la década de los veinte en Bogotá, que a la vez tienen ecos y vínculos con los mecanismos del heteropatriarcado del mundo del siglo XXI. La deuda que dieciocho años atrás contrajo Garzón, por convicción propia, con 
Eva Pinzón y Raquel Sarmiento, está saldada. Empero, la deuda que tenemos con las mujeres de todos los tiempos, en especial del nuestro y sobre todo con nosotras mismas, sigue pendiente. Como nos exhorta Teresa Garzón al final del libro, empecemos a cuestionarnos nuestros supuestos y asumamos la responsabilidad que nos corresponde como sujetas de la historia que debieran gozar de la realidad y las formas que nos merecemos. 